Check for updates

Cite this: Phys. Chem. Chem. Phys., 2018, 20, 6735

Received 15th November 2017 Accepted 26th January 2018

DOI: $10.1039 / c 7 c p 07685 a$

rsc.li/pccp

\section{Hydrogen bonding effect between active site and protein environment on catalysis performance in $\mathrm{H}_{2}$-producing [NiFe] hydrogenases $\dagger$}

\author{
Siyao Qiu, ${ }^{a}$ Luis Miguel Azofra, (D) ${ }^{\text {ab }}$ Douglas R. MacFarlane (D) *ab and \\ Chenghua Sun (D) *c
}

\begin{abstract}
The interaction between the active site and the surrounding protein environment plays a fundamental role in the hydrogen evolution reaction (HER) in [NiFe] hydrogenases. Our density functional theory (DFT) findings demonstrate that the reaction Gibbs free energy required for the rate determining step decreases by $7.1 \mathrm{kcal} \mathrm{mol}^{-1}$ when the surrounding protein environment is taken into account, which is chiefly due to free energy decreases for the two $\mathrm{H}^{+} / \mathrm{e}^{-}$addition steps (the so-called $\mathbf{~ N i}-\mathbf{S I} \mathbf{a}_{\mathbf{a}}$ to $\mathbf{I} \mathbf{1}$, and $\mathrm{Ni}-\mathrm{C}$ to $\mathrm{Ni}-\mathrm{R}$ ), being the largest thermodynamic impediments of the whole reaction. The variety of hydrogen bonds ( $\mathrm{H}$-bonds) between the amino acids and the active site is hypothesised to be the main reason for such stability: $\mathrm{H}$-bonds not only work as electrostatic attractive forces that influence the charge redistribution, but more importantly, they act as an electron 'pull' taking electrons from the active site towards the amino acids. Moreover, the electron 'pull' effect through $\mathrm{H}$-bonds via the $\mathrm{S}^{-}$in cysteine residues shows a larger influence on the energy profile than that via the $\mathrm{CN}^{-}$ligands on Fe.
\end{abstract}

\section{Introduction}

Like many enzymes, hydrogenases, catalysing the reversible hydrogen evolution reaction (HER), exhibit remarkable catalytic properties including low over-potentials and high turnover frequencies. ${ }^{1-3}$ Moreover, they typically only contain earthabundant metals, and may represent an alternative to the expensive noble-metal catalysts, e.g., $\mathrm{Pt},{ }^{4,5}$ for large-scale production. A variety of bio-inspired catalysts have been synthesised in previous works in order to mimic the active site of hydrogenases. ${ }^{6}$ However, none of the molecular catalysts show performance as impressive as that of the enzyme, making the function of the protein environment around the active site an intriguing and important question.

[NiFe] hydrogenases are one type of hydrogenase enzyme (the others are $[\mathrm{FeFe}]$ and $[\mathrm{Fe}]$ types). ${ }^{7,8}$ However, only bimetallic $[\mathrm{NiFe}]$ and $[\mathrm{FeFe}]$ hydrogenases catalyse the reversible hydrogen

\footnotetext{
${ }^{a}$ School of Chemistry, Faculty of Science, Monash University, Clayton, VIC 3800 , Australia. E-mail: Douglas.MacFarlane@monash.edu; Fax: +61 39905 4597; Tel: +61 399029916

${ }^{b}$ ARC Centre of Excellence for Electromaterials Science (ACES), School of Chemistry, Faculty of Science, Monash University, Clayton, VIC 3800, Australia ${ }^{c}$ Department of Chemistry and Biotechnology, Swinburne University of Technology, Hawthorn, VIC 3122, Australia. E-mail: chenghuasun@swin.edu.au

$\dagger$ Electronic supplementary information (ESI) available: Theoretical framework, analysis of other conceptual DFT properties, and Cartesian coordinates for the TS. See DOI: $10.1039 / \mathrm{c} 7 \mathrm{cp} 07685 \mathrm{a}$
}

splitting reaction into protons plus electrons, while the $[\mathrm{Fe}]$ hydrogenases merely activate the $\mathrm{H}_{2}$ under the presence of the substrate methenyltetrahydromet-hanopterin; ${ }^{9}$ additionally, [NiFe] hydrogenases show better oxygen tolerance than [FeFe] hydrogenases. ${ }^{10-12}$ Against this background, the study of bimetallic [NiFe] hydrogenases is of crucial importance, not only to understand and delve into the question of 'why Nature works in that way', but also to obtain evidence of the specific mechanisms of enzyme activity.

A similar atomic constitution of the active site of [NiFe] hydrogenases can be found, regardless of the source of the enzyme. It consists of a bimetallic four-membered ring linking the $\mathrm{Ni}$ and $\mathrm{Fe}$ metals with two $\mathrm{S}$ atoms; ${ }^{12,13}$ the latter are part of cysteine residues from the protein environment. The exocyclic ligands of $\mathrm{Ni}$ are another two cysteine residues (via their $\mathrm{S}$ atoms), while those of $\mathrm{Fe}$ are inorganic ligands: two $\mathrm{CN}^{-}$and one $\mathrm{CO} .{ }^{12} \mathrm{In}$ this context, the configuration of the three diatomic inorganic ligands has been studied by computational calculations for the three possible structural conformations. The "best fitted" structure is then derived by comparing such calculations with the experimental Fourier transform infrared (FTIR) spectroscopy measurements of the vibrations of the three diatomic ligands. ${ }^{14,15}$

The reversible hydrogen oxidation reaction takes place under an abundant dihydrogen $\left(\mathrm{H}_{2}\right)$ atmosphere, where hydrogenases stay in their active states. Hydrogenases become inactive under aerobic environments. ${ }^{13-18}$ There are three 


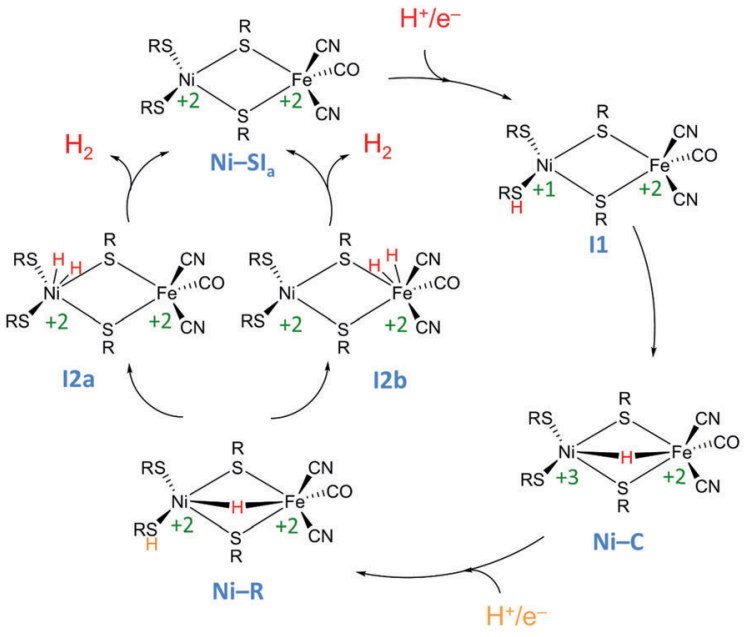

Scheme 1 Hydrogen evolution reaction (HER) path followed by [NiFe] hydrogenases.

active states that have been detected by FTIR and electron paramagnetic resonance (EPR) spectroscopies: the Ni-SIa, Ni-C, and Ni-R states. ${ }^{18-22}$ Thus, the reaction cycle shown in Scheme 1, for the specific case of the HER, could be

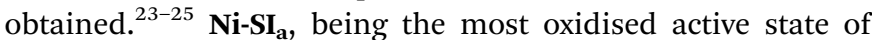
the reaction path, has no hydrogen atom bound to the active site. $^{27,28}$ The redox states of the $\mathrm{Ni}$ and Fe ions are Ni(II) and $\mathrm{Fe}(\mathrm{II}) .{ }^{26-28}$ In addition, based on Mössbauer spectroscopy, the redox state of Fe remains unchanged along the entire reaction path. $^{21,29}$

In the Ni-C state, a hydride is inserted into the fourmembered ring after the first $\mathrm{H}^{+} / \mathrm{e}^{-}$gain, bridging between the $\mathrm{Ni}$ and $\mathrm{Fe}$ ions. ${ }^{30-32}$ Correspondingly, the redox state of the $\mathrm{Ni}$ becomes $\mathrm{Ni}(\mathrm{III})$. An intermediate state, I1, is hypothesised to exist between Ni-SI a and Ni-C, ${ }^{25}$ and it has a proton bound to one of the exocyclic $\mathrm{S}$ atoms and an electron added to the $\mathrm{Ni}$ centre, leading to a reduced form, Ni(I). ${ }^{28}$ Although the so-called 'Ni-L' state has been detected in E. coli [NiFe] hydrogenases in the dark, Ni-L is only observed under illumination in most other hydrogenases. Therefore, the I1 state in this scheme is not directly related to Ni-L. Our recently published conceptual DFT results on the I1 to Ni-C stage suggest that the forming of the bridging hydride is performed as a non-synchronous two-electron transfer process, which is driven by a decrease in the electronic potential as well as by an important decrease in the electrophilicity index of the $\mathrm{Ni}^{33}$ After the second $\mathrm{H}^{+} / \mathrm{e}^{-}$ adding, the active site evolves to the Ni-R state. ${ }^{34-36}$ In this state, the proton will be added to the aforementioned exocyclic $\mathrm{S}$ atom, and the electron will be delivered to the $\mathrm{Ni}$ atom, returning it to the $\mathrm{Ni}$ (II) redox state. The X-ray crystallographic study on the Ni-R state in [NiFe] hydrogenases suggests that Cys546 is the site of protonation. ${ }^{36}$ Afterwards, the proton and the hydride tend to move to one of the metal ions, thus forming a $\mathrm{H}_{2}$ molecule, suggesting a second intermediate state known as I2, which is therefore postulated to exist between Ni-R and

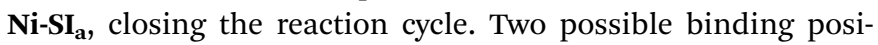
tions for the $\mathrm{H}_{2}$ molecule have been proposed by $\mathrm{Wu}$ et al., corresponding to the so-called I2a $\left(\mathrm{H}_{2}\right.$ binds on $\left.\mathrm{Ni}\right)$ and $\mathbf{I} 2 \mathbf{b}$ (on Fe), respectively. ${ }^{37,38}$ From our previous work on the energy profile of [NiFe] hydrogenases, Ni binding is thermodynamically more favourable than binding to Fe, and the singlet path is preferred over the triplet path. ${ }^{39}$

Though the active site is widely accepted as the origin of enzymatic activity for HER catalysed by [NiFe] hydrogenases, it is well known that the protein matrix plays a key role in the reaction pathway: it transmits the reactants and products throughout the entire reaction, acting as the product channel and the electron/proton pathways; it also tunes the behaviour of the active site. ${ }^{40-44}$ Previous work concluded that the protein environment can constrain the geometry of the active site, and consequently affect the reaction. ${ }^{45}$ Also, the protein presents a cage effect, that is, the protein around the active site works as a cage to prevent the proton from diffusing away. ${ }^{46}$

Although the protein environment can directly affect the catalysis performance of enzymes, the electrostatic effect of the protein on the active site, and its influence on the reaction, is not yet clearly understood. ${ }^{47}$ Previous QM/MM calculations suggest that the protein surrounding the active site affects the energy profile. ${ }^{48-50}$ Given that most hydrogenases show almost no over-potential in HER processes, ${ }^{51,52}$ further understanding of the effects of the amino acids on the active site could help explain why bio-inspired molecular catalysts rarely achieve the low over-potentials of hydrogenases. It is worth pointing out that the protein has been proposed to act as an electrostatic field, and various electrostatic models have been theoretically studied for decades; these models have been divided by Warshel et al. into macroscopic, simplified dipolar, and microscopic all-atom models. ${ }^{53}$ Of these, macroscopic models in which the protein is described as a continuum low dielectric medium have been most commonly used. ${ }^{54,55} \mathrm{How}^{-}$ ever, there is no universal dielectric constant for different protein models. Therefore a microscopic model, containing detailed information about the hydrogenase enzyme, is needed. However, microscopic all-atom models require extensive computational resources. Hence, in the present paper, the electrostatic effect of the protein environment has been studied using a model that contains the active site and the first amino acid shell, focusing on the interaction between the amino acid shell and the active site. ${ }^{31,36}$ Also, different types of amino acids have been separately studied to understand their different influences on the catalytic performance of the enzyme in the HER. $^{31}$

\section{Computational details}

Calculations of the geometries of the HER pathway followed by [NiFe] hydrogenase enzymes have been conducted by means of density functional theory (DFT) using the BP86 functional. ${ }^{56,57}$ Two effective core potential basis sets, Def2TZVPP and Def2SVP, have been applied for all models: Def2TZVPP was used for the active site (including the metals and sulphurs, and three inorganic ligands on the Fe ion), and the smaller Def2SVP for the remaining 
atoms. ${ }^{58}$ The choice of the functional and basis sets is supported by the previous calculations. ${ }^{28,35,59}$ The EDIIS/CDIIS procedure has been applied for the self-consistent field (SCF) in all cases. ${ }^{60}$ Also, to obtain the free energy and confirm the nature of the stationary points, frequency calculations have been done for all the models. According to the previous paper, considering same atoms are kept frozen during each step and a relatively large model is applied for the calculation, the vibrational frequencies of the frozen atoms are nearly unaffected by the reaction change at the active site, and therefore they could be neglected when calculating the free energy difference between the consecutive steps. ${ }^{61}$ Grimme's D3 damping function has been used for the correction of the dispersion interaction for all models in the geometry optimisation. ${ }^{62}$ The Synchronous Transit-Guided Quasi-Newton (STQN) method (QST3) has been applied for the location of the transition states (TS). ${ }^{63}$

In all cases, free energies under mild conditions of temperature $(T=298.15 \mathrm{~K})$ include vibrational zero-point energy (ZPE) corrections. For the $\mathrm{H}^{+} / \mathrm{e}^{-}$pair adding steps, the chemical potential of the $\mathrm{H}^{+} / \mathrm{e}^{-}$pair has been calculated as half the chemical potential of $\mathrm{H}_{2}$, under a standard atmosphere and at $\mathrm{pH}=0$, i.e., at computational hydrogen electrode (CHE) conditions $^{64-66}$ [see eqn (1)].

$$
\mu\left(\mathrm{H}^{+}+\mathrm{e}^{-}\right)=\frac{1}{2} \mu\left(\mathrm{H}_{2}\right)
$$

However, since enzymes work at $\mathrm{pH} \sim 7, \mathrm{pH}$ corrections have been carried out, with a value of $+9.55 \mathrm{kcal} \mathrm{mol}^{-1}$, based on the Nernst equation [see eqn (2)] as:

$$
\Delta G_{\mathrm{rxn}}=\Delta G_{0}+2.303 \mathrm{RT} \mathrm{pH}
$$

For calculations under solvent conditions, the polarizable continuum model (PCM) was applied in this work with different dielectric constants representing pentylamine $(\varepsilon=4.20)$, water $(\varepsilon=78.36)$, and $n$-methyl-formamide mixture $(\varepsilon=181.56)$ solvents. ${ }^{67}$ Also, the PCM correction with pentylamine solvent has been used for the large model calculations, as pentylamine has a static and optical dielectric constant of 4.2 and 2.1, which is similar to the protein environment. ${ }^{68}$

All energy calculations were carried out using the Gaussian09 package (revision D.01). ${ }^{69}$ Also, natural bond orbital (NBO) analysis (performed at the same computational level with the NBO 6.0 program $^{70}$ and the atom in molecules (AIM) method (via the AIMALL program $)^{71}$ were used to calculate the orbital and electron density parameters for the H-bonds, respectively.

The initial calculation models were built based on the X-ray crystallographic data provided by Higuchi et al. for the reduced [NiFe] hydrogenase from Desulfovibrio vulgaris str. 'Miyazaki F' organism (PDB accession code $1 \mathrm{H} 2 \mathrm{R}){ }^{72}$ The model under study in this work includes the active site and the first amino acid shell around it. For comparative purposes in elucidating the protein-environment effect, a model containing only the active site, as studied in one of our recent publications, ${ }^{39}$ is also presented and discussed. To distinguish the two models, the one just including the active site is labelled 'Small', while that which also includes the first amino acid shell is named 'Large'.

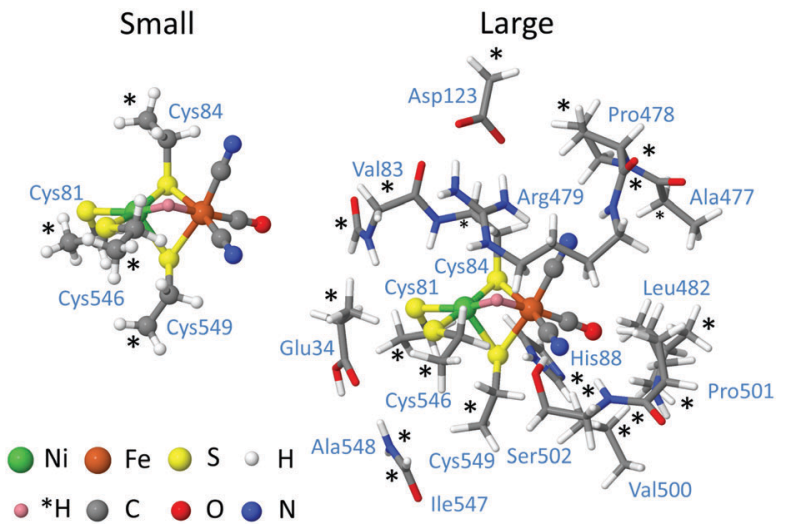

Fig. 1 The 'Small' (left) and 'Large' (right) models ( $\mathbf{N i - S I}$ a structure) studied in the present work. Asterisks $\left(^{*}\right)$ refer to atoms frozen to keep the same structure-reactivity pattern as that in the [NiFe] hydrogenase enzyme from Desulfovibrio vulgaris.

Particular atoms in the models have been fixed during optimization and frequency calculation for imitating the omitted protein matrix. The motion of the frozen atoms is hypothesised to be mostly constrained with the omitted protein matrix existence, therefore the imaginary frequencies coming from the frozen atoms should not be considered during the frequency calculation. ${ }^{23,32,37,73}$

The so-called 'Small' model comprises the four directly ligated Cys81, Cys84, Cys546, and Cys549 residues (40 atoms for the Ni-SI $\mathbf{~}_{\mathbf{a}}$ state), while the named 'Large' model comprises the 'Small' model plus the truncated Glu34, Val83, His88, Asp123, Ala477, Pro478, Arg479, Leu482, Val500, Pro501, Ser502, Ala548 and Ile547 residues extracted from the X-ray structure of the [NiFe] hydrogenase from Desulfovibrio vulgaris str. 'Miyazaki F' organism (180 atoms for the Ni-SIa state), shown in Fig. 1. ${ }^{32,72}$ All these amino acids are neutral, with the exception of Asp123 and Arg479, which are negatively and positively charged, respectively. Due to instabilities in the positively charged His88 during optimisation (the proton on His88 delivers to Cys549), His88 is not protonated in the Large model. Therefore, although Glu34 is negatively charged at $\mathrm{pH}=7$, it has been modified to be neutral in the Large model so as to retain the same total charge, ' -2 ', as in the Small model. ${ }^{32}$ Singlet (Ni-SI $\mathbf{a}, \mathbf{N i - C}$, and Ni-R) and doublet (I1 and I2) multiplicities are studied in this work, supported by our previous calculations. ${ }^{39}$

\section{Results and discussion}

Previously, Torrent et al. proposed that the amino acid environment helps tune the geometry of the active site. ${ }^{45}$ Recently, Bruschi and co-workers proposed that such geometry tuning improves the $\mathrm{H}_{2}$ cleavage reaction on the active site of [NiFe] hydrogenases. ${ }^{27}$ However, our previous study of the active site of [NiFe] hydrogenases found obvious differences in the energy profiles obtained with and without interaction of amino acids with $\mathrm{CN}^{-}$ligands at the active site, although the geometries were almost the same. ${ }^{39}$ Clearly, as well as constraining the 
geometry of active sites, amino acids have additional effects on the reaction. To understand the amino acid effect on the active site of [NiFe] hydrogenases, the so-called Small and Large models have been theoretically studied and compared in the present work. Through detailed comparison of the structural and energy aspects of the HER obtained with the Small and Large models, we will clarify how different types of amino acids (charged, hydrophobic, polar, and H-bonding) affect the catalysis at the active sites. As shown below, charge redistribution through electrostatic interactions and direct electron transfer between the core and the protein surroundings are key effects.

\subsection{Catalytic performance}

We start with calculations of the five stable states of the HER cycle; the optimised geometries were presented in ref. 39 for the Small model and are in Fig. 2 for the Large model. Initially, the $\mathbf{N i - S I} \mathbf{a}_{\mathbf{a}}$ state has no hydrogen atom bound to the active site. The first $\mathrm{H}^{+} / \mathrm{e}^{-}$addition yields the $\mathbf{I} 1$ state, with the proton binding to one of the exocyclic S atoms of the Cys546 residue and the electron going to $\mathrm{Ni}$, modifying its charge state from $\mathrm{Ni}(\mathrm{II})$ to $\mathrm{Ni}(\mathrm{I})$. Then, the proton and two electrons at the active site will experience a transfer to the bridging position between $\mathrm{Ni}$ and $\mathrm{Fe}$ (Ni-C). It is worth mentioning that the $\mathrm{Ni}-\mathrm{H}$ distances in both models (1.60 and 1.61 for Small and Large) are close to what has been measured experimentally $(1.63 \mathrm{~A}),{ }^{74}$ indicating that the amino acids around the active site do not have significant influence on the geometry of the active site. After that, the second $\mathrm{H}^{+} / \mathrm{e}^{-}$is added (Ni-R) and goes to the same $\mathrm{S}$ atom from the Cys546 residue to subsequently form $\mathrm{H}_{2}$ on the

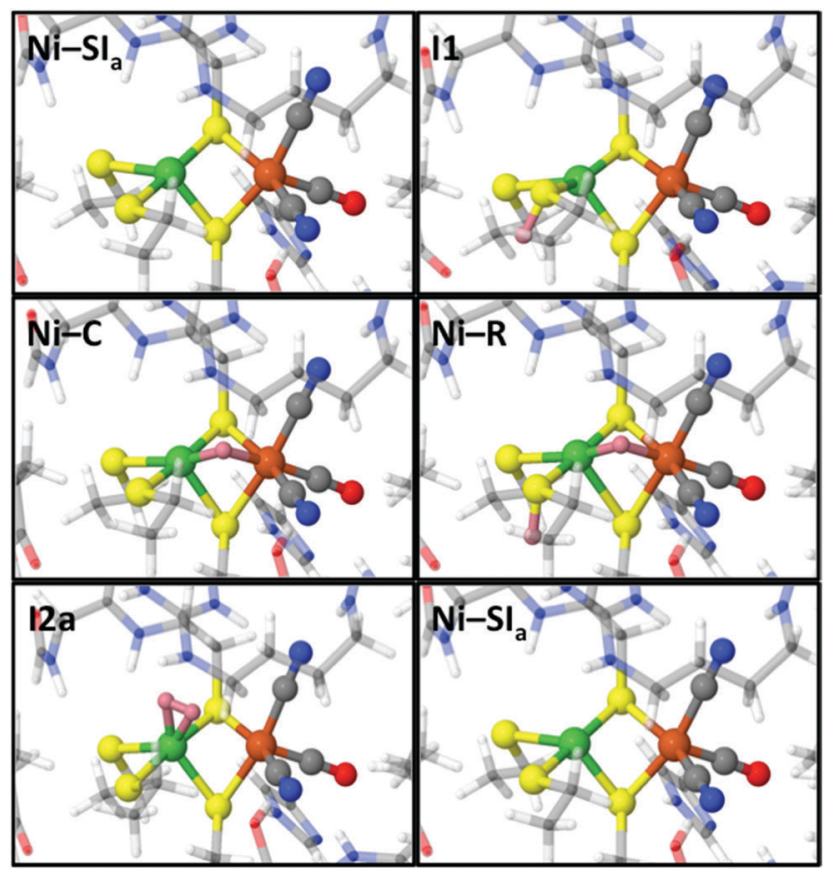

Fig. 2 Structures corresponding to the minimum energy path (singlet multiplicity) for the HER in the Large model of [NiFe] hydrogenase. Reactive $\mathrm{H}$ atoms are highlighted in pink.

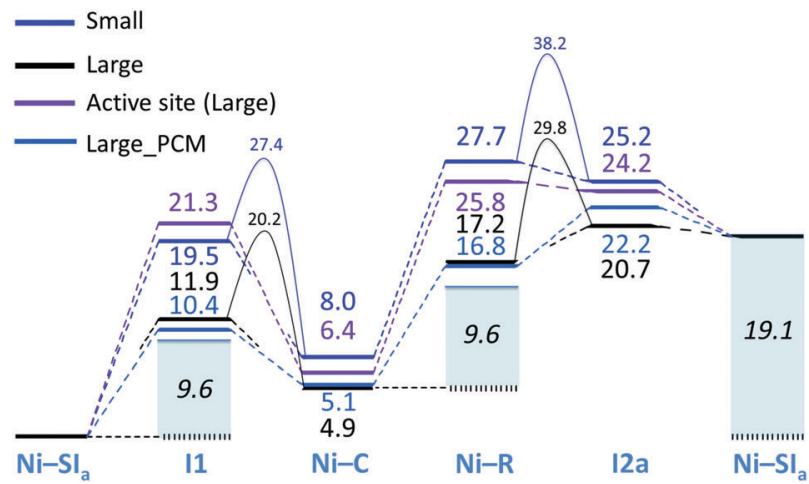

Fig. 3 Reaction Gibbs free energies $\left(\mathrm{kcal} \mathrm{mol}^{-1}\right)$ for the HER in the Small (blue) and Large (black) models of [NiFe] hydrogenase. For comparative purposes, the energy profile for the model just containing the active site of the Large model without the amino acids is indicated in lilac. pH corrections for enzymatic conditions $(\mathrm{pH}=7)$ are highlighted in light blue.

$\mathrm{Ni}$ atom (I2a) followed by its release to return the original enzyme (Ni-SI $)_{\mathbf{a}}$ ).

Upon examining the reaction Gibbs free energy results gathered in Fig. 3, the two profiles corresponding to the Small and Large models exhibit important differences. Firstly, the explicit treatment of the protein environment through the Large model suggests far better performance in catalysing the HER. In the Small case, the reaction energies required for the first and second $\mathrm{H}^{+} / \mathrm{e}^{-}$addition steps (Ni-SI $\mathbf{I}_{\mathbf{a}}$ to $\mathbf{I} \mathbf{1}$, and $\mathbf{~ N i - C}$ to $\mathbf{N i - R}$ ) are 19.5 and $19.7 \mathrm{kcal} \mathrm{mol}^{-1}$, respectively, giving these steps the largest thermodynamic impediments of the reaction cycle. The other three steps are exergonic, especially I1 to Ni-C, where the proton transfers to the bridging position to form a hydride, with a corresponding energy release of $11.5 \mathrm{kcal} \mathrm{mol}^{-1}$. The transition state searches for the I1 to Ni-C and Ni-R to I2a state found that the activation energies for the two processes are 7.9 and $10.5 \mathrm{kcal} \mathrm{mol}^{-1}$, respectively. However, the Large model tells a slightly different story, in which the energies required for the two $\mathrm{H}^{+} / \mathrm{e}^{-}$additions notably decrease to 11.9 and $12.3 \mathrm{kcal} \mathrm{mol}^{-1}$; this must be related to the amino acids facilitating the proton attachment to $\mathrm{S}$. Thus, the thermodynamic impediment drops by up to $7.5 \mathrm{kcal} \mathrm{mol}^{-1}$ with the surrounding amino acids. The proton transfer (I1 to $\mathbf{N i - C}$ ) and the $\mathrm{H}_{2}$ release (I2a to $\mathbf{~ N i - R}$ ) steps remain exergonic, while the $\mathrm{H}_{2}$ forming step (Ni-R to I2a) becomes endergonic, with an energy requirement of $3.5 \mathrm{kcal} \mathrm{mol}^{-1}$. Moreover, the energy release decreases, with an energy change of $-7.0 \mathrm{kcal} \mathrm{mol}^{-1}$ associated with the proton transfer (I1 to Ni-C). This also suggests a smaller energy requirement for the reverse dihydrogen oxidation reaction $\left(\mathrm{H}_{2}\right.$ cleavage $)$ compared with $-11.5 \mathrm{kcal} \mathrm{mol}^{-1}$ in the Small model. The activation energies for the I1 to Ni-C and Ni-R to I2a steps of the Large model are 8.3 and $12.6 \mathrm{kcal} \mathrm{mol}^{-1}$. Thus, the ratedetermining step switches from the Ni-C to Ni-R step in the Small model to the Ni-R to I2a step in the Large model for HER. The transition state geometries are not shown in Fig. 2, while the geometry coordinates could be found in the ESI. $\dagger$ Also, the energy for the rate-determining step has decreased by $7.1 \mathrm{kcal} \mathrm{mol}^{-1}$ when taking into account the amino acid 
environment, which is mainly due to the obvious decrease of the $\mathrm{H}^{+} / \mathrm{e}^{-}$injection step. Assuming that the rest of the protein around the first amino acid shell acts as a solvent with a dielectric constant around 4 , such a protein environment slightly changes the energy profile (see Large_PCM profile in Fig. 3).

To further support our hypothesis that the amino acid environment does more than simply stabilise the active-site geometry, a Small model that retains the geometry of the active site in the Large model, [named as Active Site (Large) in Fig. 3] has been also calculated. Results clearly indicate that although the geometry of the active site is retained as it was modelled in the Large model, the energy profile is closer to that of the original Small model than it is to the Large one. This is further evidence that the protein environment affects the reaction occurring at the active site.

From the Mulliken spin analysis on the five active states, the spin of Ni in the $\mathbf{I}$ and Ni-C states is 0.5884 and 0.4835 in the Small model, and the spin of Fe is 0.0005 and 0.0399. Also, no spin has been found in the Ni-SI $\mathbf{a}_{\mathbf{a}}$, Ni-R and $\mathbf{I 2 a}$ states in unrestricted BP86 calculations. Thus, the spin changes agree with the charge changes for different states, as suggested in Scheme 1.

\subsection{Unravelling the role of amino acids}

To better understand the reasons for such energy profile changes, the amino acids in the first amino-acid shell around the active site were divided into 'Charged', 'Hydrophobic', 'Polar', and 'H-bonding' species (see Fig. 4). We then compared these with the Active Site (Large) and Large models to understand which factors have the most effect on transforming the former into the latter. While keeping the geometries of the amino acids and the active site in the Large model, the free energy profiles of the four models were calculated, and they are shown in Fig. 4. We see that charged and hydrophobic amino acids have little influence on the active site. The profile associated with the Charged model (active site plus Asp123 and Arg479 residues) shows a similar trend to that of the Active Site one, with an energy difference of less than $1.9 \mathrm{kcal} \mathrm{mol}^{-1}$ (Ni-SI $\mathbf{a}_{\mathbf{a}}$ to I1) between the two models for each step. As for the Hydrophobic model, it is even more similar to the Active Site profile.

In contrast, the polar amino acids have a far more significant impact on the energy, the Polar model being within $1.4 \mathrm{kcal} \mathrm{mol}^{-1}$ of the Large model at all steps. However, in the H-bonding model, which comprises six selected polar amino-acid fragments that also form hydrogen bonds (H-bonds) with the active site, a similar energy profile to that of the Polar model was seen (Fig. 4). The remaining three polar amino acids were also calculated with the active site, but its energy profile almost overlaps with the Active Site (Large) profile (see Fig. S1, ESI $\dagger$ ). This clearly implies that hydrogen bonding between the amino acids and the active site is the most important effect of the amino acid environment, especially in reducing the energy needed for the two $\mathrm{H}^{+} / \mathrm{e}^{-}$addition steps. In this regard, we hypothesise that H-bonds might change the charge distribution, withdrawing charge from the active site to the protein environment, and thus facilitating the two $\mathrm{H}^{+} / \mathrm{e}^{-}$additions.

\subsection{H-Bonds and electrostatic effects}

The H-bonds between the amino acids and the active site have been confirmed by calculations of the electron densities using

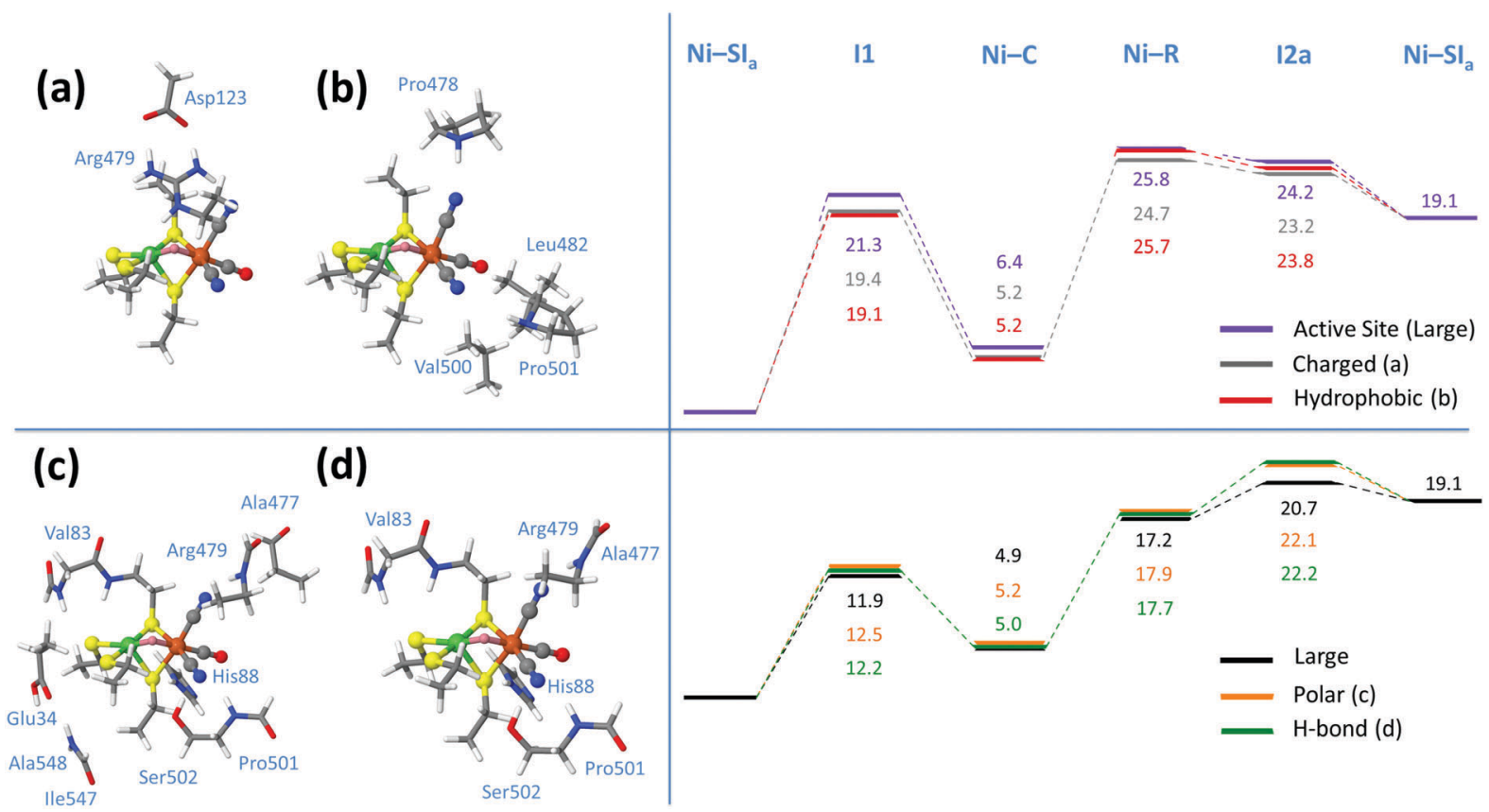

Fig. 4 [NiFe] hydrogenase models (I1 structures) containing the active site and the: (a) charged; (b) hydrophobic; (c) polar; and (d) H-bonding amino acids. Reaction Gibbs free energy comparisons (in $\mathrm{kcal} \mathrm{mol}^{-1}$ ) between these models and the Active Site (Large) and Large models. The models have been separated vertically into two groups for clarity, note that the energy profiles on the top and bottom have the same initial and final state; a plot of the energy profiles on a common scale is presented in Fig. S7 (ESI†). 
the AIM approach. As indicated in Fig. S3 in the ESI, $\dagger$ three main types of $\mathrm{H}$-bonds can be highlighted as the most important non-covalent interactions between the amino-acid shell and the active site: $\mathrm{O} \cdots \mathrm{H}, \mathrm{N} \cdots \mathrm{H}$, and $\mathrm{S} \cdots \mathrm{H}$ types. $\mathrm{O} \cdots \mathrm{H}$ acts as the connection between Asp123 and Arg479. Of the other two types of $\mathrm{H}$-bonds, those in which acidic $\mathrm{H}$ from the amino acids interacts with the $\mathrm{CN}^{-}$inorganic ligands on $\mathrm{Fe}$ are stronger interactions. Electron densities and corresponding Laplacians of these two types at the bond critical points (BCP) are both approximately reciprocal with the bonding distance (see Fig. S2, ESI $\dagger$ ), while under the same distance conditions, the H-bonds via sulphur show stronger bonding with the amino acids than those via $\mathrm{CN}^{-}$.

Among the stronger $\mathrm{H}$-bonds found, each $\mathrm{CN}^{-}$ligand presents two interactions with the protein environment; that with the side-chain of Ser502 shows the strongest interaction of this kind, as indicated by the shortest bonding distance (1.70 ̊). The electron densities of the critical points between Ser502 and the active site are around 0.05 a.u., while the rest of the $\mathrm{H}$-bonds between the amino acids and the active site are about 0.02 a.u. According to previous studies on $\mathrm{H}$-bonds, the electron densities that range from 0.02 to $0.05 \mathrm{a}$.u. belong to the moderate H-bonds. ${ }^{75-77}$

To test the hypothesis that the protein might work through electrostatic attraction to redistribute the charge at the active site, polarizable continuum model (PCM) calculations on the Small model were performed, because the PCM can mimic an electrostatic field around the active site. Under the water solvent conditions, the two $\mathrm{H}^{+} / \mathrm{e}^{-}$additions were significantly promoted (19.5 and 19.7 in vacuum $v s .15 .3$ and $16.6 \mathrm{kcal} \mathrm{mol}^{-1}$ with solvent) while the $\mathrm{H}_{2}$ forming step was not $(-2.5 \mathrm{vs}$. $2.3 \mathrm{kcal} \mathrm{mol}^{-1}$ ) in terms of the Gibbs free energy (see Fig. S3, $\mathrm{ESI} \dagger$ ). The natural bond orbital (NBO) analysis on the Small vacuum and PCM models shows an average of about $0.1 e$ charge difference on the atoms at the active site. Because the PCM works mainly as an electrostatic field, and the calculation yields similar changes in energy to those produced by including the amino-acid environment, it seems as though the main mechanism through which the protein environment affects the energy profiles is via changing the charge distribution at the active site. However, such electrostatically induced charge redistribution is not the only reason for the energy change, because when a larger dielectric constant solvent mimicking a higher electrostatic field, like $n$-methyl formamide mixture $(\varepsilon=181.5)$, is applied with the Small model, the energy profile is almost identical to that obtained with the implicit water solvent (see Fig. S3, ESI $\dagger$ ). Therefore, it is hypothesised that the charge extraction of electrons by the amino acids from the active site through the $\mathrm{H}$-bonds is of more significance than the effects of pure electrostatic attraction.

NBO calculations were performed for the Small and Large models along the reaction cycle. The charge sums of the active core site (including the two metals, binding hydrogens, the three inorganic ligands and the four sulphur atoms) in the Small model are $-1.5509,-1.5586,-1.5463,-1.5443$, and $-1.5283 e$ for the Ni-SI ${ }_{\mathbf{a}}, \mathbf{I 1}, \mathbf{N i - C}, \mathbf{N i - R}$, and I2a states, respectively; while in the Large case they are $-1.4578,-1.4476$, $-1.4449,-1.4112$, and $-1.4218 e$. Therefore, a less negative total charge of the active site is produced when the amino acids are included in the calculation; this agrees with the idea that the protein environment acts as an electron 'pull' in [NiFe] hydrogenases. The same trend is observed when comparing the active site including the four cysteine carbon skeletons, in which the total charge is -2 in the Small model, and around -1.5 in the Large model. Also, the charge change between Ni-SI $\mathbf{a}_{\mathbf{a}}$ and $\mathbf{I} \mathbf{1}$ is less negative in the Large model $(-0.0077 e$ in Small vs. $0.0102 e$ in Large), as is that for the Ni-C to Ni-R steps (0.0020 $e$ in Small vs. $0.0337 e$ in Large). From the free energy calculation on the different states of the active site with ' -1 ' and ' -3 ' total charge, the charge switches from ' -2 ' to ' -1 ' are exergonic, while the change from ' -2 ' to ' -3 ' is endergonic (see Table S1, ESI $\dagger$ ). Therefore, the less negative charge change is hypothesised to be energetically favourable. The protein environment therefore not only works as an electron 'pull', but also as an electron 'bank' - 'depositing' or 'withdrawing' electrons when needed.

To further support this hypothesis, the Small model with ' -1 ' total charge has been modelled, as shown in Fig. 5. The energy required for the two $\mathrm{H}^{+} / \mathrm{e}^{-}$additions dramatically decreases from 19.5 and $19.7 \mathrm{kcal} \mathrm{mol}^{-1}$ to 5.1 and $5.2 \mathrm{kcal} \mathrm{mol}^{-1}$. Although removing one electron from the active site facilitates the $\mathrm{H}^{+} / \mathrm{e}^{-}$addition, such a change will impede the transfer of the proton to the hydride and, especially, the forming of the $\mathrm{H}_{2}$; this $\mathrm{H}_{2}$ formation then becomes the largest thermodynamic impediment in the reaction cycle, with an energy requirement of $13.2 \mathrm{kcal} \mathrm{mol}^{-1}$. The Mulliken spin densities of the $\mathrm{Ni}$ and Fe centres are 0.3588 and 0.0426 in the Ni-SI $\mathbf{a}_{\mathbf{a}}$ state, respectively, indicating the redox states of $\mathrm{Ni}$

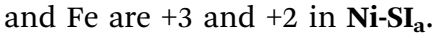

It seems that the energy profile trends for the Small model with -1 total charge follow those of the Large model-removing an electron facilitates $\mathrm{H}^{+} / \mathrm{e}^{-}$additions but impedes $\mathrm{H}_{2}$ formation. This may imply that the charge extracted by the protein environment may be optimised to balance the competing effects on $\mathrm{H}^{+} / \mathrm{e}^{-}$additions and $\mathrm{H}_{2}$ formation. The fractional charge change of the active site was related to the energy for the first $\mathrm{H}^{+} / \mathrm{e}^{-}$adding using facilities provided by the Vienna Ab-Initio Simulation Package (VASP) $)^{78-81}$ to reveal that the

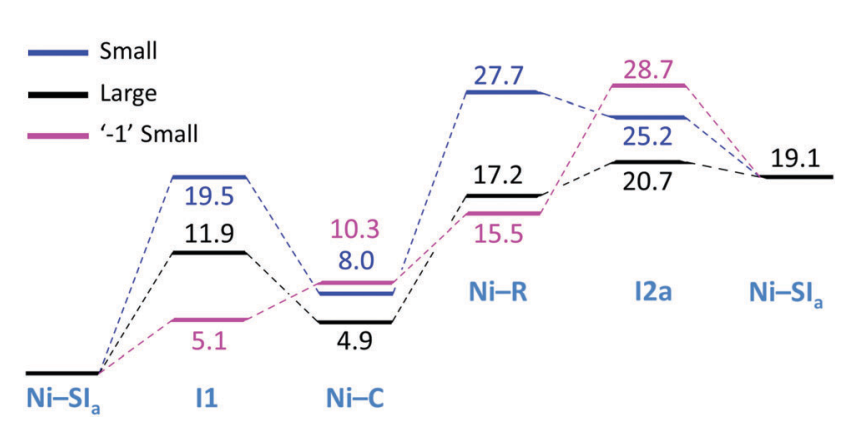

Fig. 5 Gibbs free energy profile $\left(\mathrm{kcal} \mathrm{mol}^{-1}\right)$ for the Small, Large, and -1 Small models. 
energy changes steadily from endergonic to exergonic regimes as the charge changes from -2 to -1 (see Fig. S4, ESI $\dagger$ ), reinforcing our previous idea. This result is also reflected in the analysis of the molecular orbital changes (see Fig. S5, ESI $\dagger$ ). Thus, the highest occupied molecular orbital (HOMO) energy in the Large model at the Ni-SI $\mathbf{a}_{\mathbf{a}}$ state is about $34 \mathrm{kcal} \mathrm{mol}^{-1}$ higher than in the -1 Small model, and $56 \mathrm{kcal} \mathrm{mol}^{-1}$ lower than in the classical Small model. In the case of the lowest unoccupied molecular orbital (LUMO), its energy in the Large model is between those of the -1 Small and the classical Small models. It is worth mentioning that the difference in the HOMO-LUMO gap in each state between Large and Small models is much smaller than with the Small -1 model, with an average of $2 \mathrm{vs} .74 \mathrm{kcal} \mathrm{mol}^{-1}$. This could be explained by the very similar locations of the HOMO and LUMO in the Large and Small models. Thus, the protein environment could decrease the energy of the electronic orbitals but will not change the electronic configuration of the orbitals.

The effects of the charge on the active site on the $\mathrm{H}^{+} / \mathrm{e}^{-}$ addition can be separated into effects on proton addition and the effects on electron injection. The proton addition under ' -1 ' and ' -2 ' charge conditions has been studied by means of the energy profile for the proton approaching the binding sulphur (see Fig. S6, ESI $\dagger$ ). The profile demonstrates that the energy changes induced by the charge variation are less than the $14.4 \mathrm{kcal} \mathrm{mol}{ }^{-1}$ energy change found for the first $\mathrm{H}^{+} / \mathrm{e}^{-}$ addition; therefore, the change in charge of the active site has a more significant effect on electron injection, that is, the valence state change from $\mathrm{Ni}(\mathrm{II})$ to $\mathrm{Ni}(\mathrm{I})$, than it does on proton addition.

Calculations on models including the H-bonding amino acids with $\mathrm{CN}^{-}$or $\mathrm{S}^{-}$ligands have also been done (see Fig. S1, ESI $\dagger$ ). Although a slightly stronger bond is seen between the $\mathrm{CN}^{-}$ligands and active site than between the active site and the $\mathrm{S}^{-}$ligands, the hydrogen bonding via $\mathrm{S}^{-}$atoms is more effective at promoting the two $\mathrm{H}^{+} / \mathrm{e}^{-}$additions (15.4 vs. 15.8 and 15.8 vs. $17.8 \mathrm{kcal} \mathrm{mol}^{-1}$ ), suggesting that withdrawing some electron density from the $\mathrm{S}^{-}$atom has a deeper influence on the HER. The $\mathrm{S}^{-}$ligands are directly bound to the Ni centre, while the $\mathrm{CN}^{-}$ligands bind to Fe. This could be interpreted as indicating that the ligand environment of $\mathrm{Ni}$ is more important for the $\mathrm{H}^{+} / \mathrm{e}^{-}$addition than that of $\mathrm{Fe}$, which agrees with our observation that the redox state of $\mathrm{Ni}$ clearly affects the $\mathrm{H}^{+} / \mathrm{e}^{-}$addition.

\section{Conclusions}

In summary, the protein environment can dramatically affect the energy profile in [NiFe] hydrogenases via hydrogen bonding. This conclusion comes from the energy profile comparison between the so-called 'Small' (only including the active site) and the 'Large' models, the latter comprising the active site and the first neighbouring amino acid shell. The rate-determining step in the Large model decreases by $7.1 \mathrm{kcal} \mathrm{mol}^{-1}$ compared with the Small model, which is mainly due to the free energy decrease of the thermodynamic impeditive steps in the Large model, being the two $\mathrm{H}^{+} / \mathrm{e}^{-}$addition steps (Ni-SI $\mathbf{a}$ to I1, and Ni-C to Ni-R), which drop dramatically to 11.9 and $12.3 \mathrm{kcal} \mathrm{mol}^{-1}$ in the amino acid environment. By dividing the amino acids into several models, we found that strong hydrogen bonding between the polar amino acids and the active site shows the most significant influence on the energy profile, yielding an energy profile very similar to that of the Large model. Therefore, hydrogen bonding between the active site and the amino acids is the main reason for the energy profile change. Further calculations reveal that geometric distortions caused by the protein environment are not the main reason for the energy profile changes seen in this work. Instead, charge redistribution has been identified as the key reason for the energy profile change.

Charge redistribution could occur because of electrostatic attraction associated with strong H-bonds. PCM calculations reveal that the electrostatic effect has a similar effect to that of the protein environment, reducing the free energies of the two $\mathrm{H}^{+} / \mathrm{e}^{-}$adding steps and inhibiting $\mathrm{H}_{2}$ formation. However, even with an extraordinarily high dielectric constant, we still could not mimic the energy change that comes from the protein environment, suggesting that the electrostatic effect is not the only reason for the charge redistribution.

Another mechanism for charge redistribution is direct charge transfer between the active site and the environment. In contrast with the pure electrostatic interaction, this case results in a net change of charge states for the active site; specifically, the active site in the Large model is less negative than in the Small one. It is proposed that the protein environment may act as an electron 'pull', taking the electron from the active site through hydrogen bonding and leading to a different charge distribution. Using the Small model with the ' -1 ' charge state as a test, it was found that the two $\mathrm{H}^{+} / \mathrm{e}^{-}$adding steps became less endergonic, with energy requirements of 5.1 and $5.2 \mathrm{kcal} \mathrm{mol}^{-1}$, while the $\mathrm{H}_{2}$-forming step became endergonic, with a free energy of $13.2 \mathrm{kcal} \mathrm{mol}^{-1}$. Both results agree with the energy profile changes caused by the protein environment. Therefore, we assume that besides the electrostatic effect, amino acids play a key role through $\mathrm{H}$-bonds in moving the electron outwards from the active site to improve the energy profile.

\section{Conflicts of interest}

There are no conflicts to declare.

\section{Acknowledgements}

The authors acknowledge the Australian Research Council (ARC) for its support through the Australian Centre of Excellence for Electromaterials Science (ACES), Discovery Project (DP130100268), Future Fellowship (CS, FT130100076) and Laureate Fellowship (DRM) schemes. The National Computational Infrastructure (NCI), which is supported by the Australian Government, and the Monash eResearch Centre and eSolutions-Research Support Services through the use of the 
Monash MASSIVE clusters and Campus HPC Cluster are also acknowledged for providing the computational resources. Gratitude is also due to Prof. Dr Ibon Alkorta (IQM-CSIC) for his assistance in the analysis of the noncovalent interactions. We thank Katherine Nairn and Dr Seth Olsen for advice on our manuscript. Thanks also to Prof. Wolfgang Lubitz and Prof. Olaf Rüdiger for helping us with the understanding of the overpotential data of hydrogenases.

\section{Notes and references}

1 A. Volbeda, M.-H. Charon, C. Piras, E. C. Hatchikian, M. Frey and J. C. Fontecilla-Camps, Nature, 1995, 373, 580-587.

2 A. Volbeda, E. Garcin, C. Piras, A. L. de Lacey, V. M. Fernandez, E. C. Hatchikian, M. Frey and J. C. FontecillaCamps, J. Am. Chem. Soc., 1996, 118, 12989-12996.

3 F. Dole, A. Fournel, V. Magro, E. C. Hatchikian, P. Bertrand and B. Guigliarelli, Biochemistry, 1997, 36, 7847-7854.

4 B. E. Conway and B. V. Tilak, Electrochim. Acta, 2002, 47, 3571-3594.

5 J. K. Nørskov, T. Bligaard, A. Logadottir, J. R. Kitchin, J. G. Chen, S. Pandelov and U. Stimming, J. Electrochem. Soc., 2005, 152, J23-J26.

6 G. A. N. Felton, C. A. Mebi, B. J. Petro, A. K. Vannucci, D. H. Evans, R. S. Glass and D. L. Lichtenberger, J. Organomet. Chem., 2009, 694, 2681-2699.

7 P. M. Vignais and B. Billoud, Chem. Rev., 2007, 107, 4206-4272.

8 W. Lubitz, H. Ogata, O. Rudiger and E. Reijerse, Chem. Rev., 2014, 114, 4081-4148.

9 S. V. Hexter, F. Grey, T. Happe, V. Climent and F. A. Armstrong, Proc. Natl. Acad. Sci. U. S. A., 2012, 109, 11516-11521.

10 T. Burgdorf, O. Lenz, T. Buhrke, E. van der Linden, A. K. Jones, S. P. J. Albracht and B. Friedrich, J. Mol. Microbiol. Biotechnol., 2005, 10, 181-196.

11 C. Tard and C. J. Pickett, Chem. Rev., 2009, 109, 2245-2274.

12 J. C. Fontecilla-Camps, A. Volbeda, C. Cavazza and Y. Nicolet, Chem. Rev., 2007, 107, 4273-4303.

13 H. Ogata, S. Hirota, A. Nakahara, H. Komori, N. Shibata, T. Kato, K. Kano and Y. Higuchi, Structure, 2005, 13, 1635-1642.

14 A. Volbeda, L. Martin, C. Cavazza, M. Matho, B. W. Faber, W. Roseboom, S. P. Albracht, E. Garcin, M. Rousset and J. C. Fontecilla-Camps, J. Biol. Inorg. Chem., 2005, 10, 239-249.

15 M. van Gastel, M. Stein, M. Brecht, O. Schröder, F. Lendzian, R. Bittl, H. Ogata, Y. Higuchi and W. Lubitz, J. Biol. Inorg. Chem., 2006, 11, 41-51.

16 A. L. De Lacey, V. M. Fernández, M. Rousset and R. Cammack, Chem. Rev., 2007, 107, 4304-4330.

17 A. Pardo, A. De Lacey, V. Fernández, Y. Fan and M. Hall, J. Biol. Inorg. Chem., 2007, 12, 751.

18 P. E. M. Siegbahn, C. R. Chim., 2007, 10, 766-774.

19 B. Bleijlevens, B. Faber and S. Albracht, J. Biol. Inorg. Chem., 2001, 6, 763-769.
20 C. Fichtner, C. Laurich, E. Bothe and W. Lubitz, Biochemistry, 2006, 45, 9706-9716.

21 W. Lubitz, E. Reijerse and M. van Gastel, Chem. Rev., 2007, 107, 4331-4365.

22 M.-E. Pandelia, H. Ogata, L. J. Currell, M. Flores and W. Lubitz, Biochim. Biophys. Acta, 2010, 1797, 304-313.

23 P. E. M. Siegbahn, Adv. Inorg. Chem., 2004, 56, 101-125.

24 M. Bruschi, G. Zampella, P. Fantucci and L. De Gioia, Coord. Chem. Rev., 2005, 249, 1620-1640.

25 P. E. M. Siegbahn, J. W. Tye and M. B. Hall, Chem. Rev., 2007, 107, 4414-4435.

26 H. Wang, C. Y. Ralston, D. S. Patil, R. M. Jones, W. Gu, M. Verhagen, M. Adams, P. Ge, C. Riordan, C. A. Marganian, P. Mascharak, J. Kovacs, C. G. Miller, T. J. Collins, S. Brooker, P. D. Croucher, K. Wang, E. I. Stiefel and S. P. Cramer, J. Am. Chem. Soc., 2000, 122, 10544-10552.

27 A. Pardo, A. De Lacey, V. Fernández, H.-J. Fan, Y. Fan and M. Hall, J. Biol. Inorg. Chem., 2006, 11, 286-306.

28 M. Bruschi, M. Tiberti, A. Guerra and L. De Gioia, J. Am. Chem. Soc., 2014, 136, 1803-1814.

29 K. K. Surerus, M. Chen, J. W. van der Zwaan, F. M. Rusnak, M. Kolk, E. C. Duin, S. P. J. Albracht and E. Muenck, Biochemistry, 1994, 33, 4980-4993.

30 M. Stein and W. Lubitz, Phys. Chem. Chem. Phys., 2001, 3, 5115-5120.

31 S. Foerster, M. Gastel, M. Brecht and W. Lubitz, J. Biol. Inorg. Chem., 2005, 10, 51-62.

32 M. Kampa, W. Lubitz, M. van Gastel and F. Neese, J. Biol. Inorg. Chem., 2012, 17, 1269-1281.

33 S. Qiu, L. M. Azofra, D. R. MacFarlane and C. Sun, Phys. Chem. Chem. Phys., 2016, 18, 15369-15374.

34 A. L. De Lacey, A. Pardo, V. M. Fernandez, S. Dementin, G. Adryanczyk-Perrier, E. C. Hatchikian and M. Rousset, J. Biol. Inorg. Chem., 2004, 9, 636-642.

35 T. Kramer, M. Kampa, W. Lubitz, M. van Gastel and F. Neese, ChemBioChem, 2013, 14, 1898-1905.

36 H. Ogata, K. Nishikawa and W. Lubitz, Nature, 2015, 520, 571-574.

37 H. Wu and M. B. Hall, C. R. Chim., 2008, 11, 790-804.

38 J. M. Keith and M. B. Hall, Inorg. Chem., 2010, 49, 6378-6380.

39 S. Qiu, L. M. Azofra, D. R. MacFarlane and C. Sun, ACS Catal., 2016, 6, 5541-5548.

40 X. Li, L. W. Chung, P. Paneth and K. Morokuma, J. Am. Chem. Soc., 2009, 131, 5115-5125.

41 Y. Higuchi, H. Ogata, K. Miki, N. Yasuoka and T. Yagi, Structure, 1999, 7, 549-556.

42 I. Fdez. Galván, A. Volbeda, J. C. Fontecilla-Camps and M. J. Field, Proteins: Struct., Funct., Bioinf., 2008, 73, 195-203.

43 I. Sumner and G. A. Voth, J. Phys. Chem. B, 2012, 116, 2917-2926.

44 M. McCullagh and G. A. Voth, J. Phys. Chem. B, 2013, 117, 4062-4071.

45 M. Torrent, T. Vreven, D. G. Musaev, K. Morokuma, Ö. Far-kas and H. B. Schlegel, J. Am. Chem. Soc., 2002, 124, 192-193. 
46 O. Gutiérrez-Sanz, M. C. Marques, C. S. A. Baltazar, V. M. Fer-nández, C. M. Soares, I. A. C. Pereira and A. L. De Lacey, J. Biol. Inorg. Chem., 2013, 18, 419-427.

47 D. M. A. Smith, S. Raugei and T. C. Squier, Phys. Chem. Chem. Phys., 2014, 16, 24026-24033.

48 M. Torrent, T. Vreven, D. G. Musaev, K. Morokuma, O. Farkas and H. B. Schlegel, J. Am. Chem. Soc., 2002, 124, 192-193.

49 L. Tian and R. A. Friesner, J. Chem. Theory Comput., 2009, 5, 1421-1431.

50 R. Prabhakar, T. Vreven, M. J. Frisch, K. Morokuma and D. G. Musaev, J. Phys. Chem. B, 2006, 110, 13608-13613.

51 H. S. Shafaat, O. Rüdiger, H. Ogata and W. Lubitz, Biochim. Biophys. Acta, 2013, 1827, 986-1002.

52 P. Rodriguez-Maciá, A. Dutta, W. Lubitz, W. J. Shaw and O. Rüdiger, Angew. Chem., Int. Ed., 2015, 54, 12303-12307.

53 A. Warshel, P. K. Sharma, M. Kato and W. W. Parson, Biochim. Biophys. Acta, Proteins Proteomics, 2006, 1764, 1647-1786.

54 A. J. Russell, P. G. Thomas and A. R. Fersht, J. Mol. Biol., 1987, 193, 803-813.

55 L. Li, C. Li, Z. Zhang and E. Alexov, J. Chem. Theory Comput., 2013, 9, 2126-2136.

56 J. P. Perdew, Phys. Rev. B: Condens. Matter Mater. Phys., 1986, 33, 8822-8824.

57 A. D. Becke, Phys. Rev. A: At., Mol., Opt. Phys., 1988, 38, 3098-3100.

58 F. Weigend and R. Ahlrichs, Phys. Chem. Chem. Phys., 2005, 7, 3297-3305.

59 M. G. Delcey, K. Pierloot, Q. M. Phung, S. Vancoillie, R. Lindhac and U. Ryde, Phys. Chem. Chem. Phys., 2014, 16, 7927-7938.

60 K. N. Kudin, G. E. Scuseria and E. Cancès, J. Chem. Phys., 2002, 116, 8255-8261.

61 A. Kubas, C. Orain, D. De Sancho, L. Saujet, M. Sensi, C. Gauquelin, I. Meynial-Salles, P. Soucaille, H. Bottin, C. Baffert, V. Fourmond, R. B. Best, J. Blumberger and C. Léger, Nat. Chem., 2017, 9, 88-95.

62 S. Grimme, J. Antony, S. Ehrlich and H. Krieg, J. Chem. Phys., 2010, 132, 154104.

63 C. Peng, P. Y. Ayala, H. B. Schlegel and M. J. Frisch, J. Comput. Chem., 1996, 17, 49-56.

64 J. K. Nørskov, J. Rossmeisl, A. Logadottir, L. Lindqvist, J. R. Kitchin, T. Bligaard and H. Jónsson, J. Phys. Chem. B, 2004, 108, 17886-17892.

65 J. Rossmeisl, Z. W. Qu, H. Zhu, G. J. Kroes and J. K. Nørskov, J. Electroanal. Chem., 2007, 607, 83-89.

66 E. Skulason, G. S. Karlberg, J. Rossmeisl, T. Bligaard, J. Greeley, H. Jonsson and J. K. Norskov, Phys. Chem. Chem. Phys., 2007, 9, 3241-3250.
67 G. Scalmani and M. J. Frisch, J. Chem. Phys., 2010, 132, 114110.

68 L. I. Krishtalik, A. M. Kuznetsov and E. L. Mertz, Protein, 1997, 28, 174.

69 M. J. Frisch, G. W. Trucks, H. B. Schlegel, G. E. Scuseria, M. A. Robb, J. R. Cheeseman, G. Scalmani, V. Barone, B. Mennucci, G. A. Petersson, H. Nakatsuji, M. Caricato, X. Li, H. P. Hratchian, A. F. Izmaylov, J. Bloino, G. Zheng, J. L. Sonnenberg, M. Hada, M. Ehara, K. Toyota, R. Fukuda, J. Hasegawa, M. Ishida, T. Nakajima, Y. Honda, O. Kitao, H. Nakai, T. Vreven, J. A. Montgomery Jr., J. E. Peralta, F. Ogliaro, M. Bearpark, J. J. Heyd, E. Brothers, K. N. Kudin, V. N. Staroverov, R. Kobayashi, J. Normand, K. Raghavachari, A. Rendell, J. C. Burant, S. S. Iyengar, J. Tomasi, M. Cossi, N. Rega, N. J. Millam, M. Klene, J. E. Knox, J. B. Cross, V. Bakken, C. Adamo, J. Jaramillo, R. Gomperts, R. E. Stratmann, O. Yazyev, A. J. Austin, R. Cammi, C. Pomelli, J. W. Ochterski, R. L. Martin, K. Morokuma, V. G. Zakrzewski, G. A. Voth, P. Salvador, J. J. Dannenberg, S. Dapprich, A. D. Daniels, Ö. Farkas, J. B. Foresman, J. V. Ortiz, J. Cioslowski and D. J. Fox, Gaussian09 (revision D.01), Gaussian, Inc., Wallingford CT, 2009.

70 E. D. Glendening, J. K. Badenhoop, A. E. Reed, J. E. Carpenter, J. A. Bohmann, C. M. Morales, C. R. Landis and F. Weinhold, NBO6.0, Theoretical Chemistry Institute, University of Wisconsin, Madison, USA, 2013.

71 AIMAll, 14.11.23, TK Gristmill Software, Overland Park KS, USA, 2014.

72 Protein Data Bank, http://www.rcsb.org.

$73 \mathrm{~J}$. W. Ochterski, Thermochemistry in Gaussian, Gaussian, Inc., Wallingford, CT, 2000, pp. 1-19.

74 M. Brecht, M. van Gastel, T. Buhrke, B. Friedrich and W. Lubitz, J. Am. Chem. Soc., 2003, 125, 13075-13083.

75 R. Parthasarathi, V. Subramanian and N. Sathyamurthy, J. Phys. Chem. A, 2006, 110, 3349.

76 H. M. Lee, A. Kumar, M. Kolaski, D. Y. Kim, E. C. Lee, S. K. Min, M. Park, Y. C. Choi and K. S. Kim, Phys. Chem. Chem. Phys., 2010, 12, 6278-6287.

77 C. Pak, H. M. Lee, J. C. Kim, D. Kim and K. S. Kim, Struct. Chem., 2005, 16, 187-202.

78 G. Kresse and J. Hafner, Phys. Rev. B: Condens. Matter Mater. Phys., 1993, 47, 558-561.

79 G. Kresse and J. Hafner, Phys. Rev. B: Condens. Matter Mater. Phys., 1994, 49, 14251-14269.

80 G. Kresse and J. Furthmüller, Comput. Mater. Sci., 1996, 6, 15-50.

81 G. Kresse and J. Furthmüller, Phys. Rev. B: Condens. Matter Mater. Phys., 1996, 54, 11169-11186. 